\title{
Haití: un reto de la esperanza*
}

Randolph Gilbert

ILET

"El verano se acaba

de qué color es la estación nueva si no de esperanza..."

Anthony Phelps.

\section{A}

cinco años de la caída de Jean Claude Duvalier (1986), a dos sivos de da rebelión de los esclavos de Santo Domingo (1791), a diez años del fin de siglo y del fin del milenio, hoy más que nunca nos cabe la esperanza.

Para retomar, a grandes rasgos, el dilema que plantea el tema general de este coloquio, democracia política $y$ democracia social, esta ponencia abarca una y otra vertiente, no como una disyuntiva sino como una impres-

- Mis sinceros agradecimientos a José Casar Pérez y Carlos Márquez Padilla por su comentarios a la versión original de este documento. cindible necesidad en el caso haitiano. En los dos apartados que presentamos a continuación trataremos de esbozar, en un primer momento, lo que significa para la nación haitiana el concepto de democracia social. En seguida, analizaremos brevemente los desafios que enfrenta la recién estrenada democracia política en nuestro país.

\section{DEMOCRACIA SOCIAL}

Si se pudiera "reducir" la democracia social al acceso generalizado y disfrute, por parte de la mayoria de una nación, a los principales y necesarios satisfactores, entonces Haití está lejos aûn de llegar a este Edén.

Evidentemente, un problema conceptual común -y aún muy discutidoes la medición de aquellos satis- 
factores. Sin embargo, como lo revela el cuadro que presentamos a continuación, en ninguno de los indicadores más comúnmente aceptados el caso de Haití se revelaría problemático: una amplia gama de "indicadores de bienestar" son francamente alarmantes.

Es decir, el país heredado de $\mathbf{3 0}$ años de dictadura, está lejos de constituirse ni siquiera en un caso de desarrollo económico exitoso que amortiguara el alto costo político-social de la marginación de una sociedad, en su conjunto, de la toma de decisiones. La nación haitiana ha sido excluida -por lo pronto durante los últimos 30 años- no sólo de sus derechos ciudadanos más elementales (derechos humanos, derechos civiles) sino también de los beneficios del magro desarrollo económico que una u otra coyuntura pudiera haberle proporcionado.

Es a este nivel dónde sí creemos que se sitúa la urgencia de la democracia social en nuestro país.

Retomar el concepto en este caso es hacer patente la brecha que existe entre los "pobres" y los "no pobres". Hay, en primer lugar, un aspecto de inequidad, de injusticia social.

Franquear las barreras al "desarrolio humano" exige, irremediablemente, en el caso haitiano, asumir la ruptura con un patrón de distribución del ingreso donde alrededor del $5 \%$ de la población detenta más del $60 \%$ del ingreso nacional.

Imp̀lica también que el diagnóstico de dualidad exacerbada entre el mundo rural y el mundo urbano $(30 \%$ de la población en 1988) encuentre su solución en una nueva politica social que haga de la integración nacional una meta urgente.

La magnitud de los atrasos en términos de nutrición, salud, educación, infraestructura, no permiten opciones de inversión que resulten de las leyes del mercado. Hace falta una voluntad explícita, hecha política social, para hacer retroceder los perfiles alarmantes de privación que existen en Haití. El acceso a la salud o a la educación, por ejemplo, no pueden ser resultado de un proceso de "selección natural".

Resultará evidente que abordar el tema de la democracia social, simplemente en el contexto de lo anterior, deja sin resolver ámbitos sin duda alguna bastante conflictivos del mismo, entre otros el de la propiedad social vs. la propiedad privada. Tengo sin embargo la profunda certeza de que ésta no es la disyuntiva a la que la nación haitiana se enfrenta hoy. Más bien, existen grandes tareas que son a la vez retos nacionales y a las cuales hay que dar respuesta. Es decir habrá que asumir de manera colectiva (como nación) que éstos son algunos de los derechos ciudadanos impostergables, y como tales imprescindibles $-a$ futuro- para un mayor bienestar tanto individual como colectivo, ya sea que se busque éste a través de una mayor productividad y mejor inserción en el comercio mundial, o de mayores remuneraciones al trabajo (redistribución), o de un mejor desempeño económico. El logro de estas garantías sí son condiciones sine qua non del desarrollo integral -económico y humano-, y no a la inversa, de una nación haitiana por reconstruir, o más bien por construir. 


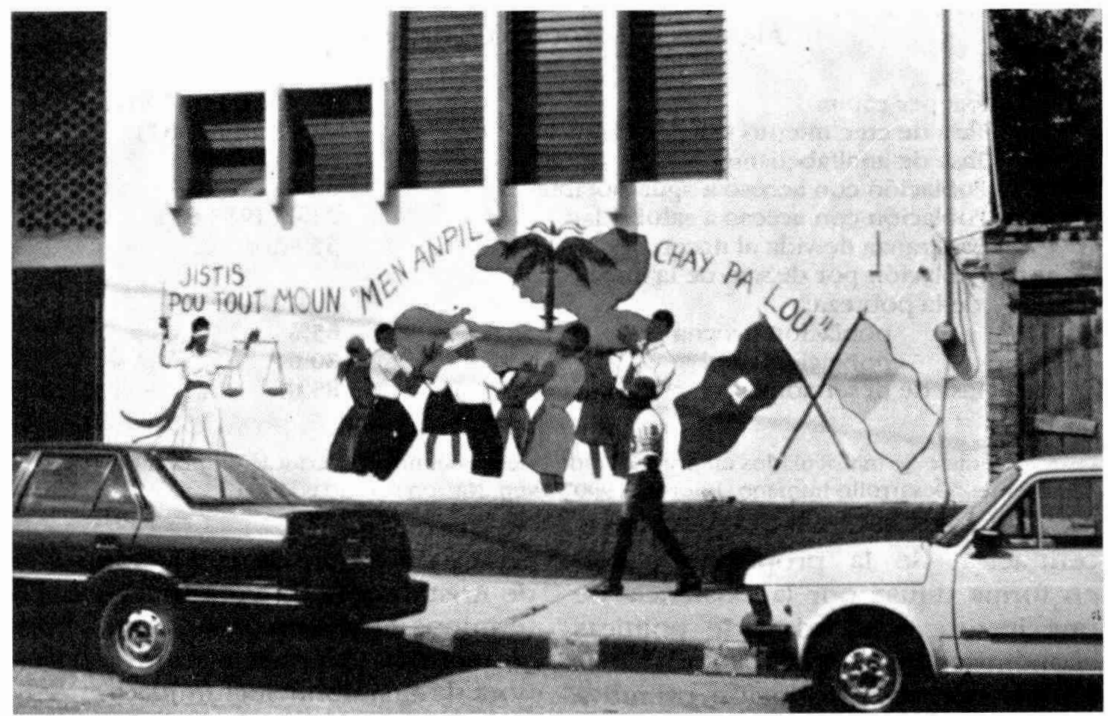

Esta nueva nación requiere como uno de sus pilares de la "justicia social, justicia como primacia del derecho, como fundamento de un estado de derecho". 1

Esta nueva nación requiere también de una descomunal participación social, sin la cual las tareas por realizar, los retos por vencer, distarían mucho de poder llegar a concretarse.

En resumen, si retomamos ahora la democracia social como una necesidad, es porque en su seno recoge, a nuestro parecer, estas dos vertientes: la participación y la justicia social.

Dejemos de lado por un momento los miedos y sepamos reconocer que, en vísperas del mundo nuevo que se

1 "Chance", 1990, p. 13. quiere forjar, hay claras evidencias de un atraso que no podemos llevar a cuestas.

Estas cargas, producto de factores tanto estructurales -la estructura agraria, el ritmo del crecimiento económico- como institucionales -las características de un Estado rapaz y depredador, las políticas públicas y el tipo de liderazgo entre otros-, se traducen en una situación de inequidad, a la que hoy en día hay que dar apremiantes respuestas.

Con mayor razón cuando la elite rentista -desde las esferas del poder político o fuera de ellas- ha influido, no sólo en "algún grado" como lo señala Fajnzylber, sino de manera sistemática "en perjuicio de la equidad, tanto directamente, por la con- 
Algunos indicadores de bienestar

- PNB per cápita

- Tasa de crecimiento PNB per cápita

- Tasa de analfabetismo

- Población con acceso a agua potable

- Población con acceso a salubridad

- Esperanza de vida al nacer

- Población por debajo de la línea de la pobreza:

población urbana población rural

- Tasa de deserción escolar*
360 dólares (1987)

$-2.1 \%(1980-87)$

$62 \%$ (1985)

$38 \%(1985-87)$

21\% (1985-87)

55 años

(1977-87):

$65 \%$

$80 \%$

$85 \%$

* Porcentaje de matriculados en primer grado que no culminan la educación primaria. Fuente: "Desarrollo humano. Informe 1990", PNUD, Naciones Unidas. 1991.

centración de la propiedad, como en forma difusa por la existencia de una institucionalidad y de políticas económicas que tienden a consolidar un sistema de distribución primitiva del poder". 2

Estas respuestas pasan, indudablemente por una respuesta politica: la implementación de esta democracia social exigía y exige una "reconciliación entre el Estado, el poder político y la nación". 3 Establecer lazos de credibilidad entre ambos es un puerto dónde asir un deseo de porvenir. La abrumadora victoria en las urnas de Jean Bertrand Aristide, el 16 de diciembre de 1990 , es incontestablemente prueba de ello.

\section{DEMOCRACIA POLÍtTCA}

La transición que emprende Haití desde la caída de Jean Claude Duvalier en febrero de 1986, llega con las eleccio-

2 Fajnzylber, "Industrialización", 1989, p. 62. 3 "Chance", 1990, p. 25. nes de diciembre de 1990 y el triunfo de Aristide a un claro parteaguas. En términos cualitativos se abre, ahora sí, una transición democrática portadora de una doble legitimidad.

En primer lugar una legitimidad institucional que le confiere el haber triunfado en las urnas con una mayoría más que significativa del electorado nacional (67\%). El deseo de alcanzar la esperanza se hizo manifiesto para un amplio sector de la población: esta oportunidad no se podía dejar, había que tomarla.

En segundo lugar una legitimidad popular. La tentativa de golpe de Estado macoute del 7 enero de 1991, antes de la toma de posesión de Aristide, es tal vez el hecho más significativo e ilustrativo al respecto. Cuando Roger Lafontant (macoute de renombre y ex ministro de los Duvalier, eliminado en la contienda electoral) intenta el golpe de fuerza de los primeros días de enero, la respuesta popular no se hizo esperar. Es el segundo refrendo a una inobjetable victoria, donde la movilización popular espontánea, sin es- 
perar ninguna convocatoria partidista o política, tomó por asalto su legítimo derecho a creer en un futuro mejor. Una sublevación general de esta magnitud puso de espaldas a la pared no sólo al régimen provisional de Ertha Trouillot, sino sobre todo al ejército: no habría retroceso en la decisión hecha voto en diciembre: sí a la esperanza, si a la dignidad recobrada. El ultimátum lanzado por la población a las autoridades lo dejó patente.

Cabe sin duda, antes de abordar los retos que enfrenta el nuevo gobierno, preguntarnos: ¿por qué ganó Aristide?

En un país que ingresaba apenas al concierto de la democracia tras largos años de dictadura, la primera transición posdictatorial reveló ser la dificil búsqueda de una salida entre las fuerzas del cambio y los defensores del statu quo, como bien lo subrayaba Johanna von Grafenstein en su ponencia de marzo de 1990.4

Los sucesivos gobiernos que desfilaron en el palacio presidencial de 1986 a 1990, desde el primer Consejo Nacional de Gobierno, pasando por Henry Namphy, Leslie Manigat, Prosper Avril y hasta llegar a Ertha Trouillot, fueron postergando y frenando las aspiraciones más urgentes de una nación sedienta de cambio, sedienta de poner fin a una era de arbitrariedad e injusticia, cuyo estigma central se resumía en el "macoutismo".

La contienda electoral de 1991 traduce a grandes rasgos el posible "embate" de las corrientes neoliberales -por llamarlas de alguna manera-que dominan el escenario con represen-

1 Grafenstein, "Haití", 1990. tacicnes partidistas o semipartidistas, 5 asentadas en una victoria anunciada: la evidente apatía de la población semanas antes del cierre del registro de electores representaba la garantía de un alto abstencionismo, lo que evidentemente jugaba a su favor.

El desinterés popular era producto de dos factores: las corrientes populares, con una relativa expresión social, no tenían hasta ese momento una expresión política, y por otra parte habian venido llamando -en su gran mayoría-a la abstención: no habiendo garantías para la realización de elecciones libres, la participación en estas condiciones implicaria legitimar un futuro gobierno producto de un "arreglo" de cúpula más que del sufragio.

En la coyuntura previa a las elecciones, como lo señala Sabine Manigat, "la búsqueda de unidad no lleva a la conjunción de las fuerzas ya estructuradas y en vías de negociación, sino a la irrupción de un elemento nuevo en el escenario electoral, el único capaz, según sus promotores, de hacer frente al peligro duvalierista: la candidatura del padre Aristide".6 Es decir, Aristide surge como una respuesta a la embestida neoduvalierista y macoute cada vez más virulenta.

La candidatura de Aristide consigue a todas luces frenar este "embate" $y$ provocar una ruptura en el "juego per-

5 En la mayoría de los casos el partido político "surge en primer lugar como una figura, una personalidad con ideas y ambiciones políticas, un candidato potencial". Manigat, "Partis", 1990, p. 18, siendo que esta definición no es exclusiva a las formaciones políticas de derecha.

${ }^{6}$ Manigat, "Partis", 1990, p. 200. 
fecto" aplicado tantas veces en nuestro continente. $Y$ es ahí donde surge el movimiento Lavalas -la avalancha-, ese caudal de espontaneidad popular que se apoya institucionalmente en Aristide, y que, a la vez, se convierte en la fuerza irresistible que lo acompaña en la búsqueda de una esperanza hasta entonces denegada.

Hoy en día, esa esperanza dejó de ser un simple anhelo: la transición democrática se hizo realidad. Pero también se hizo patente su fragilidad. Esta fragilidad no descansa sólo en las amenazas que representan aún las fuerzas más conservadoras del duvalierismo -el macoutismo- sino también en las pocas instituciones capaces de consolidar ahora la indiscutible legalidad del gobierno de Aristide, en instituciones heredadas de un régimen que había hecho de la corrupción y del nepotismo su modus vivendi, desde el aparato ejecutivo, judicial y legislativo, pasando por el ejército, hasta en amplios sectores de la sociedad civil.

Hay muchas interrogantes acerca de cómo resurgirán. La magnitud de la tarea emprendida y por emprender reclama soluciones concretas a problemas concretos: las nuevas relaciones entre el ejecutivo y el legislativo, las formas de organización -el pasar de un movimiento Lavalas a una organización Lavalas-, el papel de los parti-. dos políticos, etcétera.
Hace falta cambiar un sistema viciado desde la raíz, erigido sobre el autoritarismo y la arbitrariedad. Hay que franquear un nuevo reto: el del aprendizaje del ejercicio de la democracia, y construir para ello mecanismos de participación y organización capaces de promover la nueva nación. No hay tercera vía, entre totalitarismo y libertad hemos escogido la libertad y habrá que crearla y creer en ella con una cotidiana imaginación: "Hay que asumir el sentimiento de que la historia probablemente nos ofrece la última oportunidad de finalizar con brillo este siglo, $y$ de que no hay salvadores ni recetas hechas."7

\section{BiBLIOgRAFía}

-Fajnzylber, Fernando, "Industrialización en América Latina: de la caja negra al casillero vacío", CEPAL, 1989.

-Grafenstein, Johanna von, "Haití: crisis postdictatorial y transición democrática", Secuencia, núm. 18, septiembre-diciembre 1990 , pp. 23-36.

"La chance à prendre", Operation Lavalas, Puerto Príncipe, diciembre 1990 (edición mimeográfica).

-Manigat, Sabine, "Les partis politiques", Dossier Haiti 3, CRESDIP, Puerto Príncipe, 1990.

7 "Chance", 1990, p. 4. 